\title{
Present Status of Pre-emptive Analgesic and Its Effects on Postoperative Pain Control
}

\author{
SHOHELI ALAM ${ }^{1}$, ABU SALEH MD. WALIULLAH ${ }^{1}$, AKM SAMSUDDIN $^{2}$
}

\begin{abstract}
Pre-emptive analgesic is regularly practiced as a part of well defined protocol in most of the tertiary hospitals in developed countries. In our country most of the hospitals do not practice this. But few centers practice it irregularly without following any defined protocol. Keeping this in mind the present study was carried out to find the current practice of pre-emptive analgesic and its effects on postoperative pain control.

It was a cross-sectional study for 2 years. Sample size was 90; with a mean age of 8.7 years. Patients were selected from the department of paediatric surgery of Bangabandhu Sheikh Mujib Medical University, Dhaka, Bangladesh Institute of Child Health, Dhaka and Dhaka Medical College Hospital, Dhaka. Observation were made on pre-emptive analgesic practice regarding the agents used for analgesia, route of administration and time of administration in relation to surgery. Postoperative pain was measured on the first postoperative day by Visual Analogue Scale and was graded.

Only 17 (18.9\%) patients received pre-emptive analgesic. Among them 12 patients received local infiltration and 5 patients received caudal block. Mean value of pain score who received pre-emptive analgesic was $49.7 \mathrm{~mm}$ on the first postoperative day and which was "moderate" grade of pain. Mean value of pain score who did not receive pre-emptive analgesic was $67.0 \mathrm{~mm}$ on the first postoperative day and which was "moderate" grade of pain.

Postoperative pain control was relatively better in those patients who received preemptive analgesic. But further study should be carried out with large number of patients in different centers by using different drugs to develop a protocol for effective postoperative analgesia.
\end{abstract}

Key words: Present, pre-emptive analgesic, postoperative pain control.

\section{Introduction}

Post-operative pain is an acute pain. In addition to human sufferings associated with pain, there is now convincing evidence that unrelieved postoperative pain may result in harmful physiological and psychological effects which may cause significant morbidity and even mortality ${ }^{1}$.

Before 1980, analgesic drugs were used during postoperative period only with the idea that analgesic treatment is required when pain starts after operation. Improved understanding of peripheral and central mechanism of pain pathway, offers new treatment option. Depending on this concept, the most effective analgesia is achieved by use of pre-emptive analgesic ${ }^{2}$.

Initiating an analgesic regimen before the onset of the noxious stimulus to prevent central as well as peripheral sensitization and limit the subsequent pain

1. Resident, Department of Paediatric Surgery, Bangabandhu Sheikh Mujib Medical University, Dhaka

2. Medical officer, Department of Surgery, Shaheed Suhrawardi Hospital, Dhaka

Correspondence: Dr. Shoheli Alam experience is called pre-emptive analgesic ${ }^{3}$. The preemptive analgesia could be achieved by using different analgesic drugs that work at different sites (Figure 1 ) or by using a combination of drugs which would provide a positive synergistic action ${ }^{4}$. Pre-emptive analgesic agents, its route of administration and its dose in current practice are i) Local anasthetic agents - lidocaine and bupivacaine with or without epinephrine, ii) Opoids - morphine, meperidine (Pethidine), methadone, fentanyl, codine, iii) Nonsteroidal anti-inflammatory drugs-diclofen, paracetamol, ketorolac and tramadol ${ }^{5}$.

Effects of pre-emptive analgesics on postoperative pain control is well established by several studies ${ }^{6-8}$. Preemptive analgesic is regularly practiced as a part of well defined protocol in most of the tertiary hospitals in developed countries. In our country most of the hospitals do not practice this. But few centers practice it irregularly without following any defined protocol. Keeping this in mind our present study was carried out to find the current practice of pre-emptive analgesic and its effects on postoperative pain control. 


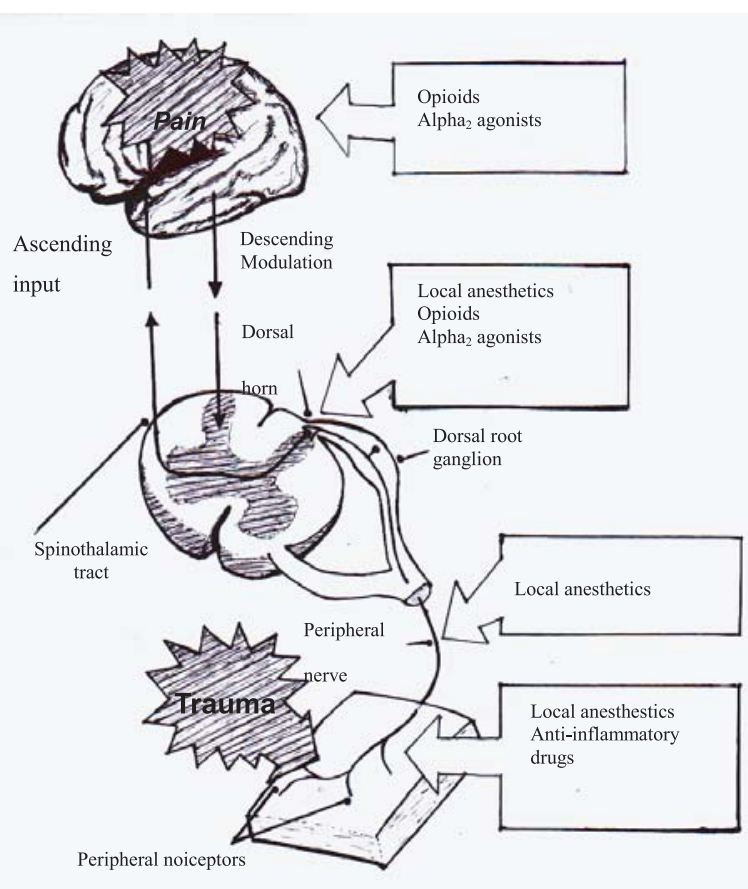

Fig.-1: Different sites of work for different pre-emptive analgesic agents

\section{Materials and Methods}

This cross-sectional study was conducted from July 2003 to June 2005 . Ninety admitted patients (30 from each hospital) were included in this study from the department of paediatric surgery of Bangabandhu Sheikh Mujib Medical University, Dhaka, Bangladesh Institute of Child Health, Dhaka and Dhaka Medical College Hospital, Dhaka.

Observations were made on pre-emptive analgesic practice regarding the agents used for analgesia, route of administration and time of administration in relation to surgery. Postoperative pain was measured on the first postoperative day by Visual Analogue Scale $(\mathrm{mm})$. Measured pain score was graded into different severities:

1. Little pain $(13.9 \pm 6.4), 2$. Some pain $(19.0 \pm 10.2)$, 3. Mild pain (19.6 \pm 10.4$)$, 4. Moderate pain $(42.8 \pm 10.7)$, 5. Severe pain $(82.9 \pm 9.6), 6$. Agonizing pain $(91.2 \pm 8.0)^{9}$.

Adequate postoperative pain control was defined as the pain score below $13 \mathrm{~mm}$ in the Visual Analogue Scale on the first postoperative day ${ }^{10}$.

Statistical analysis was done by Chi-Square and Unpaired ' $\mathrm{t}$ ' tests.

\section{Results}

Total 90 admitted patients who underwent major elective surgery were enrolled in this study. Mean age of the study population was 8.7 years (range 512 years).

All of the pre-emptive analgesics were given immediately before incision. Local anaesthetic drugs (Lidocaine with bupivacaine) were used as pre-emptive analgesic.

Among the study population only 17 (18.9\%) patients received pre-emptive analgesic (Table-I). Among them 12 patients received local infiltration and 5 patients received caudal block (Table-II).

Table-I

Frequency of pre-emptive analgesics administration

\begin{tabular}{lcc}
\hline $\begin{array}{l}\text { Pre-emptive } \\
\text { Analgesic }\end{array}$ & $\begin{array}{c}\text { No of } \\
\text { patient } \\
(\mathrm{N}=90)\end{array}$ & $\begin{array}{c}\text { Percentage } \\
(\%)\end{array}$ \\
\hline Received & 17 & 18.9 \\
Not received & 73 & 81.1 \\
\hline
\end{tabular}

Table-II

Route of pre-emptive analgesic administration

\begin{tabular}{lcc}
\hline Route & $\begin{array}{c}\text { No of patient } \\
(\mathrm{N}=17)\end{array}$ & $\begin{array}{c}\text { Percentage } \\
(\%)\end{array}$ \\
\hline Local Infiltration & 12 & 70.6 \\
Caudal Block & 5 & 29.4 \\
\hline
\end{tabular}

Mean value of pain score who received pre-emptive analgesic was $49.7 \mathrm{~mm}$ on the first postoperative day and which was found to be "moderate" grade of pain. Mean value of pain score who did not receive preemptive analgesic was $67.0 \mathrm{~mm}$ on the first postoperative day and which was found to be "moderate" grade of pain. There was significant $(P<.05)$ difference in the pain score between recipient and non-recipients of pre-emptive analgesic (Table-III). 
Table-III

Comparison of mean value of pain score by Visual Analogue Scale (VAS in $\mathrm{mm}$ ) and their grading between the recipient and non recipient of pre-emptive analgesics on the first postoperative day

\begin{tabular}{lcccc}
\hline & $\begin{array}{c}\text { No of Patients } \\
(\mathrm{N}=90)\end{array}$ & $\begin{array}{c}\text { VAS in } \mathrm{mm} \\
(\text { Mean } \pm \mathrm{SD})\end{array}$ & $\begin{array}{c}\text { Pain } \\
\text { Grading }\end{array}$ & $\begin{array}{c}\mathrm{P} \\
\text { value }\end{array}$ \\
\hline Patients with Pre-emptive Analgesic & 17 & $49.7 \pm 2.95$ & moderate & $<.05$ \\
Patients without Pre-emptive Analgesic & 73 & $67.0 \pm 3.48$ & moderate & \\
\hline
\end{tabular}

\section{Discussion}

Effective postoperative pain control remains a concern in our country even in an era when various effective pain control mechanisms are claimed to have been available.

In quest of effective pain control, the practice of postoperative analgesia in developed countries is changing fast. However, traditional practice of pain control in our country has remained same. From this stand point it was relevant to study the present status of pre-emptive analgesic and its effects on postoperative pain control in paediatric patients of our country.

In this study, it was found that twenty-four hours after surgery, postoperative pain was significantly lower $(P<.05)$ in those receiving local infiltration and caudal blockade as compared to patients who received only general anesthesia. This observation is similar to the observation made by Alsaif et al ${ }^{11}$ who found that preincisional blockade has a recognized benefit on postoperative pain control. It was found that only $18.9 \%$ patients received pre-emptive analgesic and $81.1 \%$ patients did not receive any pre-emptive analgesic, which means paediatric surgical patients were not treated by pre-emptive analgesic. This may be due to lack of universally recommended pre-emptive analgesic practice in our setting. Inadequate and improper application of knowledge regarding postoperative pain control may be one of the important factors behind it. So, many surgical teams do not consider pre-emptive analgesia on priority basis for postoperative pain control. It has been suggested by Coderre $^{12}$ that all the patients should received preemptive analgesics in order to achieve adequate postoperative pain control.

Even this 17 patients receiving pre-incisional block for pre-emptive analgesia, did not continue same block postoperatively. As a result they experienced "moderate pain" (pain score $=49.7 \pm 2.95$ ) on the first postoperative day.

Recent pain study suggests that pre-incisional block only prevents initial nociceptive input from surgical incision but cannot modulate the continued central pain sensitization initiated by inflammatory mediators after surgery. Also pre-incisional block alone fails to control the primary and secondary hyperalgesia which is responsible for "pain memory" through "wind up" mechanism. Probably this is the cause of inadequate postoperative pain control in our setting inspite of preemptive analgesic.

Woolf and Chong $^{2}$ suggest that the pre-emptive analgesic regimen should be initiated before surgery and continued throughout the postoperative day for adequate pain control.

\section{Conclusion}

Postoperative pain control was relatively better in those patients who received pre-emptive analgesic. However postoperative pain was not adequately controlled only with pre-incisional local anaesthetic. To find out effective postoperative analgesic protocol further study should be carried out with large number of patients in different centers by continuing them through early postoperative period.

\section{References}

1. Ritchey RM. Optimizing postoperative pain management. Cleveland Clin J Med 2006; 73: 72-76.

2. Woolf CJ, Chong MS. Pre-emptive analgesia Treating postoperative pain by preventing the establishment of central sensitization. Anaesth Analg 1993; 77: 362-79.

3. McQuay HJ. Pre-emptive analgesia. Br JAnaesth 1992; 69:1-3. 
4. Dahl JB, Erichsen CJ. Pain sensation and nociceptive reflex excitability in surgical patients and human volunteers. $\mathrm{Br} J$ Anaesth 1992; 69: 117- 21.

5. Landsman IS, Cook DR. Paediatric Anesthesia. In: James AOJ, Marc IR, Jay LG, Eric WF, Arnold GHC, editors. Pediatric Surgery. St. Louis Missouri, Mosby: Year Book; 1998. P. 197-208.

6. Joel LP. An Unexpected benefit of pre-emptive rectal analgesic administration : the "Key" to postoperative analgesia. Canadian Med Assoc J 2000; 12: 163.

7. Dahl JB, Kehlet $\mathrm{H}$. The value of pre-emptive analgesic in the treatment of postoperative pain. Br J Anaesth 1993; 70: 434-39.

8. Jorgen BD, Steen M. Pre-Emptive Analgesic. Br Med Bulletin 2004; 71: 13-27.
9. Sriwatanakul K, Kelvie W, Lasagna L, Calimlim JF, Weis OF, Mehta G. Studies with different types of visual analog scales for measurement of pain. Clin Pharma and Therapeutics 1983; 34: 234-39.

10. Nielsen KC, GreenGrass RA, Pietroban R, Klein $\mathrm{SM}$, Steele SM. Continuous interscalene brachial plexus blockade provides good analgesia at home after major shoulder surgery - report of four cases. Canadian J Anesth 2003; 50: 57-61.

11. Alsaif AA, Ahmad N, Nawaz S, Alotaibi W. Effect of pre-emptive bupivacaine infiltration on post thyroidectomy pain. The Inter J Anesthesiol 2005; 9: 1-5.

12. Coderre TJ, Katz J, Vaccarino AL, Melzack R. Contribution of central neuroplasticity to pathological pain, a review of clinical and experimental evidence. Pain 1993; 52: 259- 85. 